\title{
Personalidad dual y esquizofrenia en personajes de literatura centroamericana contemporánea ${ }^{1}$
}

\section{(Dual Personality and Schizophrenia of Characters in Contemporary Central American Literature)}

Junchi Sun ${ }^{2}$

Universidad de Estudios Internacionales de Shanghai, China

\begin{abstract}
RESUMen
Para el desarrollo del tema se eligió una obra costarricense y otra salvadoreña, que desde un punto de vista literario visibilizan aspectos de la sociedad centroamericana en la que existen problemas de violencia, machismo, represión social y delincuencia. Mediante un estudio comparativo y desde la teoría del rizoma, propuesta por Deleuze y Guattari, se analiza el comportamiento del protagonista de cada obra, que presenta características propias de una personalidad dual o esquizofrénica en esa sociedad.
\end{abstract}

\begin{abstract}
To approach the subject, two works were chosen, one from Costa Rica and the other from El Salvador. From a literary perspective, they illustrate aspects of the Central American society with problems such as violence, male chauvinism, social repression, and delinquency. Through a comparative study and from the perspective of rhizome theory, proposed by Deleuze and Guatarri, the behavior of the protagonist of each work is analyzed, displaying characteristics of a dual personality or schizophrenia in that society.
\end{abstract}

1 Recibido: 8 de mayo de 2019; aceptado: 10 de setiembre de 2019.

2 Departamento de Estudios Europeos y Latinoamericanos. Correo electrónico: 542216370@qq.com

LETRAS 67 (2020), ISSN 1409-424X; EISSN 2215-4094

Doi: http://dx.doi.org/10.15359/rl.1-67.3

www.revistas.una.ac.cr/index.php/letras 
Palabras clave: literatura centroamericana, violencia social, personalidad dual, esquizofrenia

Keywords: Central American literature, social violence, dual personality, schizophrenia

\section{Introducción}

La obra costarricense es De chapulines y otras langostas, de Walter J. Fernández, publicada en 2014 en San José, Costa Rica ${ }^{3}$. Se trata de un drama compuesto por cuatro escenas: (a) una enfermera que piensa y habla en solitario; (b) dos abogados, Jorge y Manuel, que discuten en su bufete; (c) un taxista pastor que predica a su cliente, un pasajero que ha cometido muchos pecados, según el taxista pastor; y (d) dos hermanos, Tony y Edy, entrabados en una discusión que tiene como fondo la agresión de parte de Tony a un chapulín (niño delincuente) y el tema de la homosexualidad. Todas las escenas se van relacionando, aunque de diferentes maneras, con un personaje central (el chapulín). El asco: Thomas Bernhard en San Salvador (1997) del salvadoreño Horacio Castellanos Moya es la otra obra elegida ${ }^{4}$ : una novela que se desarrolla en forma de monólogo de Edgardo Vega, canadiense de origen salvadoreño, obligado a retornar a San Salvador, por problemas de una herencia de la casa familiar, con la muerte de su madre. A lo largo del monólogo, Vega critica con rigor todo lo relacionado con ese país.

Hay ciertos resultados investigativos logrados desde la publicación de las dos obras: análisis de la obra costarricense desde la perspectiva del sacrificio social'; y de la obra salvadoreña desde el punto

3 Walter J. Fernández, De chapulines y otras langostas (San José, Costa Rica: Editorial de la Universidad Estatal a Distancia, 2014). Todas las citas del texto de Fernández son tomadas de esta edición. Se trata de una edición corregida y actualizada, publicada por la EUNED en 2014, de una primera publicación que vio la luz en 1986 con el título de Sobre chapulines y otras langostas, en una producción y montaje del grupo Grafitti en San José, Costa Rica.

4 Horacio Castellanos Moya, El asco: Thomas Bernhard en San Salvador (San Salvador, El Salvador: Arcoíris, 1997).

5 El trabajo académico más serio y amplio que se ha publicado sobre esta obra es de Albino Chacón Gutiérrez, «La lógica sacrificial de las sociedades contemporáneas: Sobre chapulines y langostas, 
de vista de la perversión posguerra del testimonio, el del desencanto de la realidad salvadoreña y centroamericana y el de la violencia de las palabras que usa el protagonista en su discurso ${ }^{6}$. Sin embargo, no hay estudios comparativos entre ambas obras, menos desde la perspectiva de la teoría rizomática. En eso puede estar nuestro aporte. Ésta lectura intenta mostrar que en Tony y en Vega hay un elemento en común: su personalidad dual, esquizoide. En este trabajo procuramos analizar el síndrome reflejado en los dos personajes, para compararlos, con la intención de encontrar una explicación a partir del concepto de «rizoma», tal como lo presentan y desarrollan Gilles Deleuze y Félix Guattari en Capitalismo y esquizofrenia 7.

\section{Tony en el contexto de De chapulines y otras langostas}

Edy: ... A vos siempre te ha gustado agarrarlo a uno y apretarlo. Es más, si yo me descuido me zampás un beso.

Edy: ... El tico que se besa con otro tico es playo... aunque se haga el ruso. (Agresivo) Y eso de tocarlo a uno cuando está hablando también es de playos. $\mathrm{Y}$ a vos te gusta hacer eso desde estabas carajillo $^{8}$.

Tony manifiesta tendencias homosexuales, como se lo señala su hermano Edy repetidamente. Sin embargo, Tony no lo admite y siempre busca excusas para mostrar que no lo es, como diciendo: « $\mathrm{Si}$

de Walter Fernández Arias», Drama contemporáneo costarricense, 1980-2000, Carolyn V. Bell y Patricia Fumero, eds. (San José, Costa Rica: Editorial de la Universidad de Costa Rica, 2000) 259.

6 Podemos encontrar como ejemplos algunos artículos publicados: Megan Thornton, «A Postwar Perversion of Testimonio in Horacio Castellanos Moya's El asco», Hispania 97, 2 (2014): 207219. DOI: https://doi.org/10.1353/hpn.2014.0031; Albino Chacón Gutiérrez, «El rompimiento de los espejos identitarios en Centroamérica: estudio de caso literario de un discurso migrante obsesivo: El asco: Thomas Bernhard en San Salvador, del salvadoreño Horacio Castellanos Moya», Ístmica 14 (2011): 13-22. No obstante, estos estudios se realizan desde perspectivas diferentes de la nuestra.

7 Gilles Deleuze y Félix Guattari, Mil mesetas. Capitalismo y esquizofrenia (Valencia: PRE-TEXTOS, 1994) 11-12. Todas las citas del texto de Deleuze y Gattari son tomadas de esta traducción de la obra original, Mille plateaux: capitalisme et schizophrénie (París: Éditions de Minuit, 1980).

8 Fernández, 73. En adelante, los números de página de indican entre paréntesis en el texto. 
uno no puede tocar a su hermano sin que nadie piense mal, ¿a quién puede tocar, güevón?» (73).

Se siente reprimido y tiene que contener su verdadera orientación. Se casó con una mujer y tuvo un hijo para ser considerado «normal» por los demás y ser aceptado socialmente. No obstante, por las palabras de Edy sobre la mujer de Tony, la pareja no lleva una vida sexual armoniosa; ella ha intentado seducir a Edy y «a cualquier mae que le dé pelota» (75). Tampoco Tony se siente feliz ni satisfecho porque no siente deseo sexual por una mujer, pero tampoco expresa su interés en relaciones homosexuales. Todo eso revela que el matrimonio no es sino una apariencia que lo protege de los demás.

En realidad, la represión se refleja en otro aspecto muy importante: la causada por su deseo de matar a Jefry, su propio hijo, uno de los temas centrales de la obra. Como Tony sabe que Jefry también muestra tendencias homosexuales, igual que él mismo, siente vergüenza y no quiere que se sepa. Está dispuesto a matar a su hijo para mantener el secreto y así defender «la honra de los Villalobos». Se siente muy apenado por tener un hijo "maricón", pero no puede matarlo porque lo ama, y al matarlo, él mismo perdería el sentido de seguir viviendo, por lo que también piensa en el suicidio. Si tener un hijo homosexual es penoso para él, matarlo lo sería aun más. No queda otro remedio que sufrir la aflicción; en ello radica la segunda represión para Tony. Eso se manifiesta en sus palabras y el tono con el que las profiere «Te imaginás lo que es vivir dos años queriendo matar a una persona... a una persona que uno ama» (76); «iLlevo dos años queriendo matar a Jefry!» (78); y «Hace una hora iba a matar a Jefry y después me iba a pegar un balazo yo. Es que si vos matás a un hijo, ¿para qué vas a vivir?» (78).

Tony siempre se comporta como persona reprimida, incapaz de actuar como él realmente quiere. Es débil, sensible y pasivo. Si nos preguntamos por qué Tony tiene tal carácter, hay dos principales razones: a nivel familiar y a nivel social. Por un lado, se crio en una familia con padre ausente, con una madre que nunca fue dulce ni 
tierna. Edy dice: «Mamá fue mamá y papá. Ella nos dio la fuerza que necesita un hombre». Y Tony responde: «A mí lo que me dio siempre fueron fajazos» (70). Las dos opiniones muestran que Tony resiente el daño y el castigo, mientras que Edy aprecia lo que ha hecho su madre, al convertirlo en hombre que sabe afrontar la violencia de la vida. Frente a tal madre varonil, Tony no tiene el valor de decir lo que piensa ni su tendencia homosexual, que sería inaceptable para su madre. Con esta educación, su hermano Edy se hace un hombre con toda la virilidad que se espera en una sociedad patriarcal. Edy quiere imponer su visión de la hombría a su hermano, a quien en el fondo desprecia por sus movimientos amanerados.

Por otra parte, una persona no está aislada de las estructuras sociales en que crece y se forma. La familia es una sociedad en miniatura, así que podemos ver el papel de un hombre tal como se presenta en una familia marginal típica como los Villalobos. La madre de Tony y Edy les enseña el concepto de hombría; Edy lo hereda para seguir educando a sus propios hijos de la misma manera, Por ello, no está contento con la educación que Tony da a sus hijos y quiere que este también instruya a los suyos de la misma manera: «Vos estás criando a tus hijos como maricas, bueno vos no: Irene. Y yo no quiero maricas en mi familia. Esa vara no es normal. Vos sabés que yo no voy a misa, pero creo en Dios, y eso de los maricas no tiene que ver con Dios. Nuestros hijos tienen tatas para sostenerse y crecer fuertes» (70). Es notable el contundente discurso sobre el papel de los hombres en la familia. También podemos entrever pistas del tratamiento a las mujeres por parte de los hombres. Por ejemplo, Tony describe a la mujer de Edy como «una mujer tan culona y tan tetona», y Edy describe a la de Tony como: «¿Sabés por qué nunca me he cogido a Irene? Porque no tiene nada por ningún lado» (76). Para los hombres, las mujeres se juzgan desde la apariencia y desde aquello que las conforma como apetecibles sexualmente. No es difícil ver con ello a la sociedad latinoamericana como estructuralmente machista; por eso no sorprende el saber que Tony no se atreve a mostrar su orientación homosexual. 
Todo empieza a cambiar cuando Tony ve al chapulín capturado y tirado en la calle. Tony pierde el control y actúa como una fiera: golpea y patea al niño hasta matarlo y la transformación que ocurre en su imaginario: «El chapulín ya no era el carajillo que yo ni conocía, sino era Jefry. ¿Te das cuenta, Edy? El chapulín se convirtió en Jefry. Y yo feliz porque tenía a Jefry en el suelo y podía patearlo a gusto». Como dice Tony, el chapulín es Jefry, su propio hijo, al que quiere matar. Así, mediante ese acto de sublimación, encuentra una salida para dejar libre su deseo reprimido desde hace mucho tiempo: matarse a sí mismo y matar a su hijo, matando al chapulín, que actúa como el chivo expiatorio ${ }^{9}$ de la violencia familiar y social. Con esa canalización, Tony se siente relajado y al mismo tiempo deja de ser el Tony normal que vive con una identidad de víctima y de una manera reprimida, y se convierte en alguien que se comporta como un victimario violento que cuenta con el poder y la fuerza para ejercer el daño sobre otros. La personalidad dual queda de ese modo realizada.

\section{Vega en el contexto de El asco: Thomas Bernhard en San Salvador}

El protagonista de la novela de Horacio Castellanos Moya se llama originalmente Edgardo Vega, pero vive en Montreal bajo el nombre de Thomas Bernhard, aunque nació en El Salvador. Como odia a su país, huyó a Canadá, donde obtiene la nacionalidad canadiense. Lleva dieciocho años viviendo en Montreal, donde trabaja como profesor de historia del arte en una universidad. Se trata de una profesión de prestigio, que merece el respeto de todo el mundo, al tener como temas la literatura, el arte, las humanidades y el concepto de belleza.

Sin embargo, al igual que Tony, en De chapulines y otras langostas, a Vega también le ocurre algo diferente; la causa directa es el regreso a El Salvador. Vega se ve obligado a regresar debido a la muerte de su madre, aunque no siente el deseo de hacerlo. Como su madre siempre le decía que no fuera tan ingrato, finalmente regresa

9 Chacón Gutiérrez, 259. 
cuando ella muere. El testamento de la madre establece que Vega poseerá derechos sobre la casa siempre que se presente en los funerales de ella, en la colonia Miramonte. La casa la heredan los dos hermanos y a él le corresponde decidir qué hacer con ella. Se queda en San Salvador durante un mes, lapso en el que firma documentos y realiza otros trámites para vender la casa. Lo decide así porque no quiere volver más, ni pisar de nuevo la tierra que detesta y con la que quiere cortar toda relación. De aquí se derivan testimonios de personalidad que podemos calificar como esquizoides.

A lo largo de la narración, Vega manifiesta un discurso en el que enumera todos los aspectos de El Salvador que le causan asco; por ejemplo, la cerveza Pílsener que, según él, provoca diarrea; los salvadoreños que huyeron a Montreal por la guerra le parecen siniestros y estúpidos; los ciudadanos con deseos fanáticos de ser militares que caminan, se cortan el pelo y piensan imitándolos; la preocupación por el dinero, único valor que parece existir en este país; la falta de carreras de literatura o historia, pues a nadie le interesan las humanidades sino solo aspirar a ser administradores de empresas; los políticos ignorantes que ni saben pronunciar un discurso ante el público y que matan impunemente inocentes en la guerra para luego subir al poder del Estado y saquearlo; Ivo, hermano suyo que dedica su vida a producir llaves y cerraduras, un típico negociante de clase media; las casas amuralladas, que parecen cuarteles; el fanatismo por el fútbol, que no es sino una actividad bárbara sin sentido; la hipocresía de esta raza que los lleva a desear en lo más íntimo convertirse en gringos; los médicos que solo quieren robarles dinero a los enfermos sin que les importe o no curarlos; las universidades privadas y nacionales y sus profesores; los periódicos y los editorialistas; las pupusas; el puerto La Libertad y el muelle; las telenovelas; los bares siempre bulliciosos; la detestable música folklórica; los zancudos; el calor; los taxistas; el Monumento a la Paz y al Hermano Lejano; las esculturas de los próceres en las autopistas; el entretenimiento sexual de los amigos; las discotecas y los prostíbulos... 
Todo recibe la crítica despiadada de Vega, sean personas o lugares, o las actividades o los fenómenos, sean humanos o naturales. Todo eso revela su odio y desprecio más profundos hacia el país y su pueblo y lo realiza utilizando las palabras más fuertes y feas para calificar su país: inmundicia, mugre, miasma, horrible, miseria, más estúpido, más criminal, tierra mugrosa, podredumbre, alucinación que existe solo por sus crímenes, asquerosidad, raza podrida, adulador, servil, gente vomitiva, repulsiva, un pueblo energúmeno y criminal, porquería, entre muchas otras. Toda la obra está plagada de palabras semejantes.

De lo que Vega no se da cuenta es que durante este proceso de criticar y negar todo lo que se refiera a El Salvador y su pueblo, cae también sobre él mismo, y gradual e inconscientemente ello lo convierte, en uno más de ellos, en alguien que pertenece al grupo que desprecia. Es decir, deja de ser educado, ilustrado y civilizado, y discursivamente se trasforma en un bárbaro, porque lo único que hace es negar El Salvador de una manera primitiva e irracional, lo que nos deja ver su personalidad dual. Otra cosa interesante es que en las palabras de Vega se hace mención su pasaporte canadiense; como se trata de un documento escrito, y si consideramos que el pasaporte es un símbolo de la sociedad que lo emite, al final el perder este documento es como perder la razón y la civilización y entrar en la barbarie.

\section{Tony y Vega: sus personalidades duales vistas desde la teoría del rizoma}

Aunque Tony y Vega son personajes de obras diferentes, viven en países diferentes, tienen diferentes trabajos y familias, y todo parece diferente entre ellos, no resulta difícil descubrir características comunes, sobre todo en cuanto al ámbito de sus personalidades duales: una víctima reprimida ante un victimario violento en Tony; un civilizado ante un bárbaro en Vega. Al compararlos, sabemos que ambas transformaciones de personalidad, que conviven en ellos, los llevan de un estado a su opuesto. Aspecto clave es que las conversiones de 
personalidad son inconscientes; Tony y Vega no lo hacen intencionalmente, sino que lo realizan, lo sufren, sin advertirlo. De ahí que podemos decir que Tony y Vega viven el síndrome de esquizofrenia. Nos detendremos un poco en este aspecto central para comprender de mejor manera los alcances de las dos obras y de los dos personajes.

La esquizofrenia es una enfermedad psicológica, caracterizada por el síndrome de personalidad doble, triple o múltiple. Durante años, psiquiatras y filósofos se han esforzado por explicarla desde diversas perspectivas. Una es la botánica del rizoma. Rizoma es un concepto filosófico desarrollado por Gilles Deleuze y Félix Guattari en Mil mesetas. Capitalismo y esquizofrenia (1980). Es introducido con el ejemplo de cómo escribir un libro y luego es universalizado con el mundo, porque el libro imita al mundo, como el arte a la naturaleza. Según los autores, la clásica ley del libro: libro-raíz (pivotante con su eje y las hojas alrededor, obedece la lógica binaria de la dicotomía), es caduca y manoseada y no refleja la realidad porque la naturaleza no actúa de este modo. Oponen también la segunda figura del libro: sistema-raicilla o raíz fasciculada; aunque en ella la raíz principal se ha destruido en su extremidad, en ella viene a injertarse una multiplicidad inmediata y cualesquiera de las raíces secundarias adquieren un desarrollo propio. Los autores postulan que el mundo y la naturaleza se explican por el rizoma que, en la botánica, como tallo subterráneo se distingue radicalmente de las raíces y de las raicillas porque tiene formas muy diversas, desde su extensión superficial ramificada en todos los sentidos hasta sus concreciones en bulbos y tubérculos ${ }^{10}$.

Los principios del rizoma son:

$1^{\circ}$ y $2^{\circ}$ principios de conexión y de heterogeneidad: cualquier punto del rizoma puede ser conectado con cualquier otro, y debe serlo.

10 Deleuze y Guattari, $11-12$. 
$3^{\circ}$ principio de multiplicidad: solo cuando lo múltiple es tratado efectivamente como sustantivo, multiplicidad, deja de tener relación con lo Uno como sujeto o como objeto, como realidad o espiritual, como imagen y mundo. No hay unidad que sirva de pivote en el objeto o que se divida en el sujeto. Una multiplicidad no tiene ni sujeto ni objeto, sino únicamente determinaciones, tamaños, dimensiones.

$4^{\circ}$ principio de ruptura asignificante: frente a los cortes excesivamente significantes que separan las estructuras o atraviesan una. Todo rizoma comprende líneas de segmentaridad según las cuales está estratificado, territorializado, organizado, significado, atribuido, etc.; pero también líneas de desterritorialización según las cuales se escapa sin cesar.

$5^{\circ}$ y $6^{\circ}$ principios de cartografía y de calcamonía: un rizoma no responde a ningún modelo estructural o generativo. Es ajeno a toda idea de eje genético, como también de estructura profunda ${ }^{11}$.

Deleuze y Guatarri se refieren a una «imagen de pensamiento», basada en los principios mencionados; esto es, según el funcionamiento de las células, los axones, etc., el cerebro se convierte en una multiplicidad inmersa en su plan de consistencia, todo un sistema aleatorio de probabilidades ${ }^{12}$. Cuando ambos filósofos analizan la esquizofrenia, para quienes no se trata de un trastorno mental ni una enfermedad, sino de un estado psicológico inconsciente y revolucionario de un individuo en sociedad. Este siempre trata de escapar de las reglas de la realidad y del ego restringido por ellas. En ese marco, el concepto de rizoma es el núcleo del análisis de la esquizofrenia: sería como una órbita sin centro y la forma de multiplicidad de los deseos. Diferente del árbol, con su modelo jerárquico, el rizoma tiene muchas ramas del mismo nivel; cualquier elemento puede afectar o incidir en otros. Es decir, no hay un centro ni una distinción de lo superior y lo subordinado. Los elementos son del mismo nivel y se conectan sin obstáculo, haciendo

11 Deleuze y Guatarri, 12-17.

12 Deleuze y Guatarri, 20. 
posible la fluidez de los deseos, que son el origen de la personalidad de un individuo y causando en él la esquizofrenia.

Con la teoría del rizoma, podemos explicar la esquizofrenia de Tony y de Vega. Tony es un homosexual en una sociedad latinoamericana en la que la homosexualidad no termina de ser tolerada en muchas familias, por razones religiosas o tradicionales, algunas de las cuales la toman incluso como un estado mórbido. Vivir como víctima de una manera reprimida es la condición que Tony debe vivir para insertarse en la sociedad y ser aceptado. Sin embargo, en el fondo se esconde otro deseo natural y más fiel al Tony auténtico. Como el individuo siempre trata de escapar de las reglas de la realidad y del ego restringido por ellas, con un fuerte estímulo (el encuentro con el chapulín, en este caso), se realiza la fluidez de un deseo a otro, como las ramas del rizoma, lo que desencadena un estado de violencia $-\mathrm{y}$ de autoviolencia - personal y familiar.

En el caso de Vega, este considera que «me parecía la cosa más cruel e inhumana que, habiendo tantos lugares en el planeta, a mí me haya tocado nacer en este sitio, nunca pude aceptar que, habiendo centenares de países, a mí me tocara nacer en el peor de todos, en el más estúpido, en el más criminal $\gg^{13}$. Quiere huir de él, abandonar lo que corresponde a su identidad territorial primigenia, y nunca volver a «ese lugar», pero no cuenta con que este lo habita y lo acompañará siempre, de ahí la (auto)violencia que practica, porque es algo de lo que, a pesar de todo, él tiene conciencia. La muerte de su madre lo obliga a regresar a San Salvador. En tal circunstancia, el personaje sufre ese estado básico de esquizofrenia: cuanto más quiere negar sus orígenes, cuanto más quiere escapar de él, más esquizoide se vuelve; de ahí el discurso obsesivo que lo caracteriza ${ }^{14}$. Las palabras fuertes y llenas de desprecio le sirven como un canal para la fluidez de sus propios deseos que, por otra parte, contravienen el deseo de su madre, lo cual vuelve más problemática su situación.

13 Castellanos Moya, 17.

14 Chacón Gutiérrez, «El rompimiento». 


\section{Conclusión}

La realidad es incambiable para los dos personajes (una estructura mental y familiar machista para Tony; una problemática identidad originaria para Vega); por eso, no les queda más que escapar de ella, como el rizoma, de una rama a otra, de un extremo a otro, porque todos los deseos son del mismo nivel y se conectan fluidamente. Así se comprende mejor el comportamiento de su personalidad dual y su esquizofrenia (Tony: de víctima reprimida a victimario violento, pero sin dejar de ser víctima; Vega: de bárbaro a civilizado y vuelta atrás, aunque quizás podría decirse que el viaje es también hacia dentro, hacia su interior).

Ambas obras actúan como puntos de condensación históricosocial $^{15}$, que reflejan aspectos de la sociedad costarricense, de la salvadoreña, y en general de diversas sociedades centroamericanas y hasta latinoamericanas. En De chapulines y otras langostas y en El asco: Thomas Bernhard en San Salvador, hay abundantes aspectos en los que podemos conocer la(s) sociedad(es) latinoamericana(s) contemporánea(s) en su complejidad. Aluden, al mismo tiempo, a una verdad histórica que funciona en muchas personas y lugares, de modo que valdría la pena estudiar otras obras de la narrativa latinoamericana desde la perspectiva de la teoría del rizoma. Por ejemplo, las novelas del colombiano Fernando Vallejo La virgen de los sicarios y Rosario Tijeras, algunas del mexicano Mario Bellatín, de manera particular La escuela del dolor humano de Sechuán y El salón de belleza, o bien El palacio de la risa, del chileno Germán Marín, para citar las que podrían ser estudiadas desde esta misma perspectiva.

La noción de rizoma, como elemento organizador y explicativo, permite ahondar en un fenómeno como las multiplicidades en la personalidad. Como el rizoma de una planta, cada individuo tiene al

15 La noción de punto de condensación, como una función sociohistórica de la literatura en un momento y en un lugar determinado se debe a la exposición que de esa categoría ha hecho Albino Chacón en diversos artículos. 
mismo tiempo diversos deseos en forma de ramas mentales que se relacionan y se comunican, incluso contradictoriamente, sin un centro ni una jerarquía, que fluyen de un estado a otro, lo que está en los orígenes del funcionamiento esquizoide. Surge cuando el individuo quiere escapar de las reglas de la realidad de la sociedad y de la limitación del ego situado en esa realidad. Tony y Vega son dos personajes similares paradigmáticos en cuanto a esa manifestación, pero en mayor o menor medida son rasgos de todos los seres humanos y eso es lo que otorga universalidad a los dos textos que hoy nos han ocupado. 
